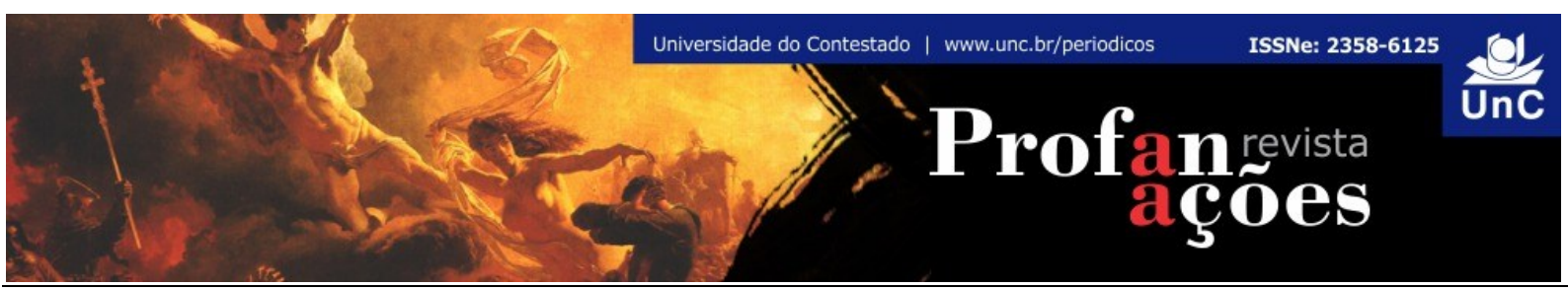

\title{
CONTRADIÇÕES DO DISCURSO POLÍTICO ENTRE A LIBERDADE DE EXPRESSÃO E O ÓDIO
}

\author{
Daniel Arruda Nascimento ${ }^{1}$ \\ Isabela Bichara de Souza Neves ${ }^{2}$
}

\begin{abstract}
RESUMO: Motivadas pela necessidade de se colocar em pauta análises sobre a atual realidade política do nosso país, as presentes linhas visam explorar as contradições do discurso político em evidência, especialmente no que diz respeito à relativamente recente proliferação do discurso de ódio entre nós. Não apenas no nosso cotidiano politizado às avessas, tornado espetacular, de identidades cultivadas na falsidade, visivelmente indigente no que se refere à capacidade de reflexão. Interessa-nos aqui, sobretudo, o discurso de ódio parlamentar, o discurso de ódio que encontra ressonância e expressão entre os representantes eleitos para fazer justiça à vontade popular no Congresso Nacional. Submetendo à acareação o reconhecimento do direito à liberdade de expressão, a garantia constitucional de imunidade parlamentar e a proliferação dos discursos de ódio com efeitos discriminatórios, teremos como propósito colocar a questão de modo transversal e inteligível. Não faltam exemplos de ódios incrustados em falas de parlamentares durante o exercício de seus mandatos eletivos, acompanhadas do incentivo à propagação da intolerância e do racismo, com a perpetuação da opressão contra cidadãos e grupos minoritários.
\end{abstract}

Palavras-chave: Política. Liberdade de expressão. Imunidade parlamentar. Discurso de ódio.

\footnotetext{
${ }^{1}$ Doutor em Filosofia pela Universidade Estadual de Campinas. Professor Adjunto do Instituto de Ciências da Sociedade da Universidade Federal Fluminense. Professor permanente do Programa de Pós-Graduação em Filosofia da Universidade Federal do Espírito Santo. Brasil. E-mail: danielarrudanascimento@id.uff.br.

${ }^{2}$ Bacharel em Direito pela Universidade Federal Fluminense. Egressa do Curso de Pós-Graduação Lato Sensu em Humanidades na Contemporaneidade da Universidade Federal do Rio de Janeiro, tendo defendido o trabalho $O$ embate entre a liberdade de expressão e a propagação de discurso de ódio num Estado Democrático de Direito: o discurso do Poder Legislativo. Advogada e residente jurídica da Defensoria Pública do Estado do Rio de Janeiro. Brasil. E-mail: belabsouza@hotmail.com.
} 


\title{
CONTRADICTIONS OF THE POLITICAL SPEECH BETWEEN FREEDOM OF EXPRESSION AND HATE
}

\begin{abstract}
Motivated by the need of bringing to discussion the analysis of Brazilian actual political reality, the following lines aim at exploring the contradictions of the political speech in evidence, especially concerning the increase of hate speech among us. Not only in our daily life, backward politicized, nowadays spectacular, full of false identities, notably poor of thinking ability. Above all, interests us here the parliamentary hate speech, the hate speech that finds echo and expression among the representatives elected in order to make justice to the popular will in the National Parliament. Putting into question the freedom of expression as a right, the parliamentary immunity as a constitutional guarantee and the dissemination of the hate speech with discriminatory effects, we have the objective of propose a reflection in a transversal e intelligible way. There is no lack of examples of hate embedded in speeches of Brazilian parliamentarians during the exercise of their elective mandates, accompanied by encouragement to spread intolerance and racism, perpetuating the oppression against some citizens and minority groups.
\end{abstract}

Keywords: Politics. Freedom of expression. Parliamentary immunity. Hate speech.

\section{INTRODUÇÃO}

Lemos em $A$ comunidade que vem de Giorgio Agamben que uma vez que o espetáculo penetrou o mundo e o tornou essa realidade espetacularizada de profusão e reprodução de imagens, o homem encontrou-se expropriado de sua potência prática, alienado do mundo político que outrora procurou construir (cf. AGAMBEN, 2001, p. 63-64). A sociabilidade humana e o apelo político que lhe é inerente não podem subsistir à supremacia da aparência sobre o que é ontologicamente relevante. Quando a representação social entre pessoas é completamente mediada por imagens, sobra muito pouco daquele mundo cujo aparecer era um revelar-se. Esse novo mundo denominado por Guy Debord de sociedade do espetáculo, esse mundo separado e organizado pelas mídias, no qual a potência humana encontra-se exilada, é o ambiente em que a forma da mercadoria e a economia mercantil assumem sem reservas o estatuto da soberania e da irresponsabilidade, o que frustra toda capacidade política. Quando o parecer ser assume inteiramente o lugar do ser, tudo o que sobra são as disputas de 
imagens produzidas ao sabor do mercado de imagens, fulminando-se as potencialidades vitais da política entre os homens.

Como procurou demonstrar a pensadora alemã Hannah Arendt, seria no espaço político, constituído por palavras e atos, o que deveria ser de qualquer modo irrenunciável para o homem, que os homens singulares manifestariam o seu quem és. Lemos no livro $A$ condição humana que é através do discurso e da ação que os homens se distinguem entre si, ao invés de permanecerem diferentes simplesmente como dois entes que pertencem à mesma espécie, e se inserem no mundo propriamente humano, afirmando a condição humana da singularidade e da pluralidade (cf. ARENDT, 2004, p. 189-191). Mesmo em um mundo desconfigurado pela profusão de imagens, todavia, os homens não podem deixar de apresentaremse aos outros como identidades físicas e pessoais, na medida em que ações e discursos estão sempre aos cuidados da leitura alheia, ainda que sujeitos a erros de leitura ou à impossibilidade de se definir. Pelo fluxo vivo dos atos e das falas, alguma identidade sempre surgirá. Por isso, podemos compreender "a razão pela qual o teatro é a arte política por excelência; somente no teatro a esfera política da vida humana é transposta para a arte" (ARENDT, 2004, p. 200).

O discurso está então dissociado da mera ideia de instrumento de comunicação entre indivíduos. Os meios de comunicação podem ser realizados de diversas formas, inclusive através de linguagens menos convencionais, porém o discurso expõe a individualidade em plena esfera pública, ainda que a teia das relações humanas esteja fragilizada por distorções no caráter da revelação, o que não é difícil ocorrer nos nossos dias de vida política. Alguma identidade aparecerá, ainda que essa identidade não revele absolutamente nada do quem és. O que já havia sido notado por Hannah Arendt no seu tempo, preocupada com a corrupção do discurso político e sua submissão a fins determinados, preocupada com o acirramento das competições entre grupos e com as dicotomias inférteis.

Sem a revelação do agente no ato, a ação perde seu caráter específico e torna-se um feito como qualquer outro. Na verdade, passa a ser apenas um meio de atingir um fim, tal como a fabricação é um meio de produzir um objeto. Isto ocorre sempre que deixa de existir convivência, quando as pessoas são meramente "pró" ou "contra" os outros, como ocorre, por exemplo, na guerra moderna, quando os homens entram em ação e empregam meios violentos para alcançar determinados objetivos em proveito do seu lado e contra o inimigo. Nestas circunstâncias, que 
naturalmente sempre existiram, o discurso transforma-se, de fato, em mera "conversa", apenas mais um meio de alcançar um fim, quer iludindo o inimigo, quer ofuscando a todos com propaganda. Neste caso, as palavras nada revelam; a revelação advém exclusivamente do próprio feito, e este feito, como todos os outros, não desvenda o "quem", a identidade única e distinta do agente (ARENDT, 2004, p. 193).

Com a submissão de meios a fins e instrumentalização de todo discurso e de toda ação, corremos o risco de perder a capacidade de revelação do homem político. Identidades reproduzidas ao infinito estarão a serviço de um ambiente político cada vez mais estéril. Especialmente se partimos do pressuposto, na sociedade espetacularizada, de que o que aparece é bom, o que é bom aparece (cf. AGAMBEN, 2001, p. 64). Se o simples fato de aparecer, potencializado pela contribuição da grande mídia, tornar tudo aquilo que aparece bom e desejável, estaremos perdidos não somente no mundo político. Por outro lado, se todo discurso e ação política tiver como objetivo primeiro o aparecer, não importa o que se diga ou o que se faça, todo discurso e toda ação estarão comprometidos, pouco espaço haverá para a revelação, menos ainda para a consideração do interlocutor e para a reflexão política. Em última análise, esvazia-se a pluralidade humana de suas potencialidades, correndo-se o risco de cancelar-se a própria pluralidade humana.

Motivadas pela necessidade de se colocar em pauta análises sobre a atual realidade política do nosso país, as presentes linhas visam explorar as contradições do discurso político em evidência, especialmente no que diz respeito à relativamente recente proliferação do discurso de ódio entre nós. Não apenas no nosso cotidiano politizado às avessas, tornado espetacular, de identidades cultivadas na falsidade, visivelmente indigente no que se refere à capacidade de reflexão. Interessa-nos aqui, sobretudo, o discurso de ódio parlamentar, o discurso de ódio que encontra ressonância e expressão entre os representantes eleitos para fazer justiça à vontade popular no Congresso Nacional. Surpreende-nos a dificuldade institucional do Poder Legislativo no controle funcional sobre o discurso de ódio dentro de sua própria estrutura orgânica, o desequilíbrio entre o uso da fala como meio legítimo para propagação de ideias políticas por parte dos parlamentares e os limites do exercício do seu direito à liberdade de expressão. Submetendo à acareação o reconhecimento do direito à liberdade de expressão, a garantia constitucional de imunidade 
parlamentar e a proliferação dos discursos de ódio com efeitos discriminatórios, teremos como propósito colocar a questão de modo transversal e inteligível.

Partimos da hipótese de que a redução das desigualdades econômicas e regionais, o reconhecimento de direitos a minorias alijadas da vida pública e a ampliação da cidadania de grupos que alcançaram algum acesso a espaços e bens culturais gerou alguma alteração na configuração da sociedade brasileira e forçou o convívio mais próximo das diferenças. Entre outras, estas podem ser algumas das razões da proliferação do discurso de ódio no atual cenário político brasileiro. As deficiências de nossa cultura política e a insatisfação geral com os governos são também pontos cruciais para se compreender a crise institucional. Com o acirramento em crescimento espiral das crises econômicas, alguns privilégios foram desafiados por riscos antes inobservados. Tudo acompanhado da caça aos culpados e da demonização do diferente. Sem embargo, a sensação compartilhada de instabilidade política e econômica ocasionou não só o surgimento de um movimento repressivo e autoritário em relação aos novos processos de evolução social, principalmente com a possibilidade do desenvolvimento de discursos que destoam, na maioria das vezes, de concepções construídas socialmente por uma parcela dominante e conservadora. A dilatação dos meios de comunicação através do uso de ferramentas disponíveis pela internet veio acentuar a produção e a distribuição dos discursos. A inovação tecnológica dos meios de comunicação possibilitou o ingresso virtual de muitas opiniões no âmbito de interatividade social, dando-se oportunidade para que cidadãos se encontrem numa rede de diálogos em suposta escala global. A construção social de valores, posicionamentos e regras que impulsionam mudanças de costumes e culturas está cada vez mais rápida e abrangente. Para não ficar de fora, o Poder Público entregou-se aos novos meios de comunicação com voracidade. Para dar visibilidade ao Poder Legislativo frente às outras entidades políticas, utilizou-se desses mecanismos comunicativos para participar do diálogo social. Embora reconheçamos o aspecto admirável desse tipo de interação entre órgãos estatais e políticos, temos acompanhado, inclusive entre parlamentares, uma onda de expressividades de cunho combativo às diferenças de opiniões, tornando o trato comunicativo com o público um verdadeiro campo minado para a nomeação dos direitos das minorias e da singularidade de pensamento. No campo político atual, a população se depara com a eterna dicotomia entre princípios 
de formação social extremamente variáveis que, se deveriam garantir a pluralidade e frutificar, acabam por impedir o entendimento pleno da condição humana e suas mazelas.

\section{A LIBERDADE DE EXPRESSÃO COMO COROLÁRIO CONSTITUCIONAL NO ESTADO DEMOCRÁTICO BRASILEIRO}

Após a histórica abertura democrática com a promulgação da Constituição da República Federativa do Brasil de 1988, diversas possibilidades de sociabilidade inerentes à condição humana em uma comunidade política foram inseridas no âmbito de uma normatividade constitucional que reconheceu como um dos seus pilares a dignidade da pessoa humana e a constituiu como um dos direitos mais protegidos. Nesse contexto, indivíduos que convivem numa sociedade essencialmente orgânica e estruturada entre classes, grupos sociais e ordens sociais são passíveis de formação de valores e opiniões que, por sua vez, se baseiam em redes de informações e dados construídos pelas reiteradas relações sociais. No acentuado processo de globalização, as interações entre diferentes tipos de indivíduos pertencentes a um complexo de culturas, escolhas e tradições entram em relação dialógica, gerando não apenas experiências sociais, mas também agrupamento de ideias e formação de movimentos que se manifestam de diferentes modos, como, por exemplo, na criação de artes, discursos coletivos e mídias.

A liberdade de expressão se apresenta como proteção útil não só para a comunicação entre os indivíduos de um mesmo núcleo social, mas também se apresenta como uma garantia individual de cada cidadão para interagir de forma plena no espaço público. A Constituição Federal de 1988 estabelece em seu texto que a liberdade de expressão deverá ser assegurada em sua forma plena e multifacetada (artigo quinto, inciso quatro, combinado com o artigo terceiro, inciso quatro), inclusive pela ingerência estatal e administrativa, impedindo-se a investida de mecanismos de repressão que possam coibir manifestações populares sobre ideias políticas, religiosas, culturais etc. Um Estado que tem como destino a democracia e a consolidação de uma sociedade fraterna, pluralista e sem preconceitos (preâmbulo), como fundamento a cidadania (artigo primeiro), como objetivo a construção de uma sociedade livre, justa e solidária, com a promoção do 
bem de todos, sem preconceitos de origem, raça, sexo, cor, idade e quaisquer outras formas de discriminação (artigo terceiro), como princípio a prevalência dos direitos humanos e o repúdio ao racismo (artigo quarto), deve estar atento à garantia da liberdade de expressão.

No que respeita à democracia, a liberdade de expressão é direito fundamental diretamente correlato à garantia de voz aos cidadãos na manifestação de suas várias correntes políticas e ideológicas. É certo que a proteção da liberdade de expressão não é suficiente para assegurar a participação popular no debate político, pois os direitos fundamentais efetivam-se de modo interdependente: a eficácia de um direito fundamental depende da eficácia dos demais. Porém, não restam dúvidas de que tal liberdade é imprescindível que aqueles que desejem manifestar-se na esfera pública tenham como fazê-lo e não sejam reprimidos por isso (TÔRRES, 2013, p. 62).

Torna-se oportuno pontuar que a liberdade de expressão advém do ímpeto íntimo de se expressar do ser humano, situando-se tudo aquilo que se diz como um produto da relação entre ação e discurso. Os atos de falar e agir perante a sociedade que desafia a existência individual efetivam a condição humana, permitem que aquele que fala e age constate a sua existência social pela autoafirmação de si como um ser diferente entre iguais. É essencial que o cidadão tenha a margem de liberdade necessária para exprimir o seu pensamento e as suas ideias, no diálogo entre a individualidade pessoal e a pluralidade dos semelhantes. A rede de relações humanas depende da capacidade do indivíduo de transpor a sua individualidade para a esfera política. A pluralidade dos homens exsurge dessa interrelação simbiótica entre o discurso e a ação.

Em sede constitucional, a liberdade de expressão está intimamente ligada à exposição de informações ao público. Historicamente, o reconhecimento do direito à liberdade de expressão foi necessário para que os movimentos sociais de minorias e grupos vulneráveis se insurgissem na arena política e provocassem a elaboração de novas concepções e instrumentos normativos, com a ampliação de direitos. A ideia do reconhecimento dos mais variados grupos sociais implicou na
necessidade de garantir a liberdade de expressão para esses segmentos
minoritários como forma de viabilizar sua participação política, com vistas à
construção de uma democracia pluralista, numa perspectiva de inclusão
social. As lutas e as exigências de justiça desses movimentos libertários
estão referidas na importância do reconhecimento de suas diversidades,
secundarizando para tanto inclusive dimensões ontológicas relevantes que 
poderiam ativar reflexões políticas mais abrangentes (exemplo: construção de um projeto comum emancipatório contra a opressão), do que uma simples retórica de conteúdo moral e apelo ao reconhecimento das diferenças. Quando se observa essa dinâmica própria dos movimentos sociais contemporâneos, constata-se a importância da qual se reveste a liberdade de expressão para a construção da democracia pluralista que se afirma na atualidade. O novo imaginário da era 'pós-socialismo', quando fez emergir movimentos emancipatórios renovou as expectativas quanto ao exercício das liberdades de pensamento. Essas liberdades transformaramse em veículos relevantes para a propagação das ideias necessárias à construção de um novo referencial para a dignidade humana, possibilitando a formação da identidade de grupo, intercâmbio de opiniões e experiências, e, ainda, a exposição de suas reivindicações (FREITAS; CASTRO, 2013, p. 343).

Devemos afastar, portanto, a pretensão que o exercício da liberdade de expressão se dê sempre de maneira harmônica. Ao contrário, a expressão de ideias sempre desafiará alguma ordem posta, causando o dissenso entre gerações e grupos sociais. Somente assim algumas minorias conquistaram historicamente a possibilidade de aparecer na esfera pública e ver seus direitos ampliados. Contudo, é preciso reconhecer que o exercício da liberdade de expressão não é absoluto. Ao se expor publicamente, num ambiente político, todo cidadão, e especialmente aqueles parlamentares que estão atuando sob o manto da legitimidade popular, deverá respeitar certos princípios que sustentam o estado constitucional de proteção aos demais cidadãos. A liberdade de expressão não é absoluta e deve levar em consideração a sua equalização com outros direitos igualmente relevantes. A liberdade de expressão ganhou contornos variáveis em relação à sua abrangência interpretativa, tendo como pressuposto o seu caráter principiológico perante outros tantos direitos fundamentais regulados pela Constituição Federal. Saber delimitar de forma coerente a expressão de uma convicção ou pensamento pode ser vital para a proteção do indivíduo em sociedade. Assim como 0 ato de se expressar abertamente em uma sociedade é importante para o desenvolvimento democrático e humano, sopesar esta liberdade com outros limites de respeito à dignidade humana passou a ser um tema de interesse social. 


\title{
A PROTEÇÃO INTERNACIONAL CONTRA TODAS AS FORMAS DE DISCRIMINAÇÃO E INTOLERÂNCIA E A GARANTIA DE IMUNIDADE PARLAMENTAR
}

A liberdade de expressão encontra respaldo normativo não apenas na Constituição da República Federativa do Brasil de 1988, mas também está devidamente protegida pelo manto dos tratados e acordos internacionais que buscam assegurar a correspondência entre os direitos humanos e as legislações dos diferentes países que compõe a comunidade internacional. Além da mobilização de institutos internos de proteção, a Comissão Interamericana de Direitos Humanos propõe-se a averiguar e fiscalizar abusos cometidos pelos Estados participantes da Organização dos Estados Americanos. Com relação à liberdade de expressão, instrumentos de coerção de práticas inibitórias tem a intenção de assegurar o seu pleno gozo na qualidade de direitos fundamentais da pessoa humana.

\begin{abstract}
A Comissão Interamericana de Direitos Humanos, seguindo o exemplo da ONU, criou em 1997 a Relatoria Especial para a Liberdade de Expressão, encarregada de assessorar a Comissão, sistematizando a jurisprudência e o conhecimento acerca do direito à liberdade de expressão e, desde 1998, também publica informes anuais, nos quais define princípios, compila as melhores práticas observadas no Continente, além de denunciar situações de abuso e violações desse direito. [...] Por outro lado, a jurisprudência da Corte Interamericana de Direitos Humanos vem desempenhando um papel decisivo no avanço do direito à liberdade de expressão. Por meio de decisões notavelmente progressistas, a Corte já teve oportunidade de condenar diversos países membros da OEA a oferecer reparação às vítimas e a efetivar políticas de proteção, além de consolidar, por meio dos fundamentos das decisões, o marco jurídico da liberdade de expressão como direito humano (BENTO, 2016, p. 94).
\end{abstract}

De acordo com a norma constitucional vigente, os tratados e acordos internacionais só passam a vigorar de forma plena no plano normativo nacional quando são submetidos a um sistema de ingresso legislativo rigoroso. A recepção de tratados e acordos internacionais deve passar pelo crivo do Poder Legislativo para fazer parte do ordenamento jurídico interno. A partir de um procedimento legiferante de caráter positivo, o conteúdo dessas tratativas entre países na proteção das liberdades do homem se faz também de conhecimento geral, para a população e para os próprios parlamentares, que terão assim que resguardá-lo tanto em sua 
atividade legislativa na feitura de leis, quanto nos debates públicos e na emissão de suas convicções.

Neste diapasão, a Convenção Americana sobre Direitos Humanos, promulgada pelo Decreto $n^{\circ}$ 678/1992, conhecida como Pacto de São José da Costa Rica e assinada mais de vinte anos antes, no dia 22 de novembro de 1969, estabelece em seu artigo 13 que a liberdade de expressão é um dos direitos humanos que devem ser respeitados pela estrutura política-administrativa do Estado ratificado, sendo imprescindível a adoção de medidas preventivas e saneadoras que protejam os indivíduos de condutas intolerantes e arbitrárias, inclusive de autoridades políticas. Eis o texto na íntegra.

\begin{abstract}
Artigo 13. Liberdade de pensamento e de expressão. 1. Toda pessoa tem direito à liberdade de pensamento e de expressão. Esse direito compreende a liberdade de buscar, receber e difundir informações e ideias de toda natureza, sem consideração de fronteiras, verbalmente ou por escrito, ou em forma impressa ou artística, ou por qualquer outro processo de sua escolha. 2. O exercício do direito previsto no inciso precedente não pode estar sujeito à censura prévia, mas a responsabilidades ulteriores, que devem ser expressamente fixadas pela lei e ser necessárias para assegurar: a) o respeito aos direitos ou à reputação das demais pessoas; ou b) a proteção da segurança nacional, da ordem pública, ou da saúde ou da moral pública. 3. Não se pode restringir o direito de expressão por vias ou meios indiretos, tais como o abuso de controles oficiais ou particulares de papel de imprensa, de frequências radioelétricas ou de equipamentos e aparelhos usados na difusão de informação, nem por quaisquer outros meios destinados a obstar a comunicação e a circulação de ideias e opiniões. 4. A lei pode submeter os espetáculos públicos a censura prévia, com o objetivo exclusivo de regular o acesso a eles, para proteção moral da infância e da adolescência, sem prejuízo do disposto no inciso 2. 5. A lei deve proibir toda propaganda a favor da guerra, bem como toda apologia ao ódio nacional, racial ou religioso que constitua incitação à discriminação, à hostilidade, ao crime ou à violência.
\end{abstract}

Diante da descrição detalhada sobre a proteção a liberdade de expressão, cabe salientar que o conceito de democracia tem como um dos seus fundamentos o exercício pleno das liberdades do indivíduo no círculo social, de modo a possibilitar o convívio plural e pacífico entre os mais variados substratos sociais. Pela redação do documento legal, a liberdade de expressão é garantida em larga extensão e toda limitação à liberdade de expressão deve ser bem fundamentada no respeito a outros direitos e valores sociais. As liberdades que integram os direitos fundamentais dos cidadãos possuem limites bem delineados a fim de impedir abusos ou comportamentos que estimulem a discriminação e a violência, estejam eles 
positivados enquanto conduta criminosa ou não. A liberdade de expressão tem que se ater à balança invisível entre a pluralidade de pensamento e manifestação de um lado e aos princípios da igualdade e da integridade por outro, que ao mesmo tempo ancoram a democracia e a previnem dos piores riscos. Ao apresentar opiniões e convicções sobre determinado fato ou assunto de repercussão social, todo falante deve estar atento para não fazer tabula rasa desse equilíbrio necessário. Nenhuma justificativa deve ser razoável para se permitir o livre curso de discursos que vão destrutivamente de encontro a outros princípios que englobam o conceito de dignidade da pessoa humana.

Assim também para a imunidade parlamentar, concebida na nova ordem constitucional brasileira para garantir as representações e falas dos parlamentares em uma democracia muito recente e ainda em desenvolvimento infantil. $A$ imunidade parlamentar se constitui em uma das prerrogativas dos membros do Congresso Nacional para a manutenção do exercício de seu mandato representativo, de acordo com a inteligência do artigo 53 da Constituição Federal. Deve ser compreendida como um instrumento da construção da democracia, uma garantia extra, ainda que permanentemente questionável em sua conveniência, de que a liberdade de expressão terá o seu lugar na casa em cujos acentos deveriam ressoar os apelos populares. A imunidade parlamentar possui o intuito de criar uma proteção invisível durante toda diplomação do congressista, evitando as investidas políticas que possam afetar ou restringir o exercício do mandato do escolhido pela democracia representativa. A possibilidade de isenção em seu discurso durante o exercício do seu mandato poderia ser importante para criar os diálogos e debates que contribuíam para o enriquecimento legislativo e desenvolvimento de políticas públicas de relevo ao cenário social. Está claro, contudo, que a imunidade material não pressupõe a ausência de limites para abusos de todo tipo, cometidos contra outros parlamentares ou contra os próprios cidadãos. De qualquer forma, toda fala parlamentar deve observar os limites impostos pela consolidação histórica e transnacional dos direitos humanos. As instituições legislativas pressupõem o respeito aos ditames constitucionais que asseguram aos cidadãos todos os direitos fundamentais a sua existência social. A representação social deve refletir os valores e as ideias inerentes a um sistema político pluralista e reconhecido pela correspondência entre pensamento político e realidade social. 
Se por um lado a imunidade parlamentar é um instituto absolutamente necessário ao regime democrático, de outro, o abuso desta garantia funcional deve ser detido, para que não venha a ensejar o enfraquecimento do mesmo, em razão de seu mau uso. Não deve e nem pode uma garantia, que é conferida no interesse do povo, servir de proteção para a prática de atos que não estão de acordo com o direito e nem com interesses de seus representados, como frequentemente tem ocorrido, e que ficaram na impunidade, abrigados sob o manto da 'imunidade', desvirtuando, assim, o instituto de sua finalidade (BOSIGNOLI, 1999, p. 39).

A oportunidade de introduzir interesses dos cidadãos nos debates de políticas públicas e na produção legislativa através da representação dos parlamentares é essencial para o desenvolvimento dos procedimentos democráticos representativos, tais como somos hoje capazes de conceber. A imunidade parlamentar, neste caso, é um pressuposto do próprio exercício da função eletiva, uma garantia de inviolabilidade que impede interferências de outros poderes constituídos na função parlamentar. O discurso dos congressistas deve então guardar relação com sua função política, sem desvios que possam agredir frontalmente o espírito da Constituição Federal e os direitos humanos. A prerrogativa não se constitui como um privilégio onipotente que exime os agentes políticos de sua responsabilidade sobre o que é dito sobre e perante os seus representados. No entanto, contrariando essa finalidade institucional, a exteriorização de pensamento por parte de representantes políticos tornou-se uma alavanca para proliferações de manifestações e de discursos opressores que visam padronizar ideologias e pensamentos discriminatórios sob o manto da legitimidade parlamentar. A imunidade é assimilada como impunidade.

\section{ALGUNS EXEMPLOS DE DISCURSOS DE ÓDIO ENTRE NOSSOS PARLAMENTARES}

Se existe uma espécie de felicidade do presente texto em encontrar exemplos que possam iluminar o que aqui se denuncia, esta felicidade é inversamente proporcional à infelicidade da realidade da nossa política. O ambiente político atual do país está tomado por diversos exemplos de parlamentares que já se manifestaram de forma discriminatória sobre filiações ideológicas, religiões, opções sexuais e condições de gênero, expressando-se com a intenção deliberada de agredir a dignidade da pessoa humana. A emissão de manifestações polêmicas e 
intolerantes vem se ampliando no Congresso Nacional nos últimos anos, causando diversos constrangimentos para a população, especialmente àquela atingida diretamente pelo discurso de ódio, na medida em que o discurso apresentado pelos congressistas possui um alto nível de repercussão nacional, muitas vezes transmitidos diretamente por meio televisivo ou via jornais de grande circulação, muitas vezes retransmitidos por canais da internet e pelas redes sociais. Para parlamentares do tipo, a imunidade parlamentar parece ser uma licença para se dizer o que quiser, muitas vezes sem aquele filtro natural que foi um dia implantando no entendimento humano, não importa o conteúdo, não importando se as ofensas deliberadas estão já bem longe das razões da liberdade de expressão.

Liberdade de pensamento é diverso de liberdade de expressão, assim como preconceito é diverso de discriminação. Preconceito é opinião ou juntada de opiniões acolhida acrítica e passivamente pela tradição, pelo costume ou por uma autoridade de quem aceitamos as ordens sem discussão, "na medida em que a aceitamos sem verificá-la, por inércia, respeito ou temor, e a aceitamos com tanta força que resiste a qualquer refutação racional, vale dizer, a qualquer refutação feita com bases em argumentos racionais" (BOBBIO, 2002, p. 103). Podemos acrescentar que preconceitos são erros que cometemos, são conceitos tomados previamente sem o devido conhecimento, por nossa iniciativa ou por influência dos outros, muitas vezes motivados por paixões, desejos ou interesses. A rigor, cada pessoa pode pensar e acreditar em qualquer coisa, isto é mesmo inevitável, mesmo que sólidos argumentos contrários já tenham lançado tal hipótese às ruínas. O que é inaceitável é que eles venham acompanhados da discriminação, ou seja, de atos e palavras que colocam o interlocutor em uma posição de inferioridade por motivo injusto, dispensando tratamento desigual a pessoas no que elas têm de iguais.

Ainda que as palavras e os atos discriminatórios tenham raízes mais profundas e sejam compartilhadas, não se pode nesses casos considerar o argumento uma excludente. A motivação dessas manifestações por parte dos congressistas pode ter origens em concepções sociais e na perpetuação da hegemonia de pensamentos discriminatórios pelas instituições sociais. O fenômeno do discurso de ódio pode ser vislumbrado cotidianamente através da perpetuação de manifestações de grupos que cultuam a intolerância religiosa, racial e de gênero, tanto em redes sociais de veiculação pela internet quanto abertamente na 
convivência social. Não estão sós os nossos parlamentares do tipo. O mais espantoso é que eles justificam suas ações julgando representar o preconceito e o discurso de ódio contra o diferente que ainda assolam o veio social tão pouco solidário que nos envolve.

Além da rapidez com que essas declarações são pulverizadas pela sociedade, os grupos minoritários se defrontam com a maximização de hostilidade por parcela da sociedade conservadora, que encontra nessas manifestações um incentivo para reafirmar o ódio e perseguir indivíduos que se identificam por concepções sociais diferentes da hegemônica. As várias etapas comunicativas de incitação, discriminação e disseminação da intolerância por parte de um determinado grupo socialmente dominante frente a minorias já marginalizadas geram inevitavelmente uma rede de estigmatização. Cria-se, assim, uma rede de intrigas e uma bipolarização dos setores sociais que acabam albergando o conteúdo emitido por parlamentares e propagando a ideia a uma única concepção excludente de estilo de vida. Por outro lado, o pensamento reducionista que macula a dignidade da pessoa humana vem surgindo no cenário político como uma forma de reprimir o direito de manifestação de grupos sociais que representam a minoria social e lutam pela extensão dos direitos de cidadania. A partir das declarações de teor discriminatório, palavras afrontosas agrupam em torno a si grupos sociais que procuram alijar outros grupos de direitos de fala perante o núcleo social. A manifestação da representatividade política e a imunidade que são concedidas constitucionalmente aos parlamentares possuem parâmetros e limites que são essenciais para reprimir abusos e evitar a supressão das liberdades individuais.

Recentemente, o deputado federal Marco Feliciano vem sofrendo diversas denúncias por parte de cidadãos e pelo Ministério Público Federal sobre a veiculação de suas opiniões através de redes sociais, manifestando opiniões discriminatórias sobre grupos homossexuais e com publicações de cunho racista, incitando a intolerância aos seus seguidores. Tais denúncias ainda não foram acolhidas pelo Supremo Tribunal Federal sob o argumento da ausência de legislação que tipifique e criminalize a conduta penalmente (cf. SUPREMO TRIBUNAL FEDERAL, 2014).

Em um fluxo de ódio semelhante, o deputado federal Jair Bolsonaro tem proferido opiniões discriminatórias sobre questões relacionadas às minorias, em 
especial aos direitos LGBT, que se reverteram numa verdadeira manifestação flagrante contra os direitos humanos. O tratamento do caso gerou a sua condenação pelo Tribunal de Justiça do Estado do Rio de Janeiro ao pagamento de indenização a título de danos morais ao Fundo de Defesa dos Direitos Difusos do Ministério da Justiça (cf. TRIBUNAL DE JUSTIÇA DO ESTADO DO RIO DE JANEIRO, 2015; GÓIS, 2015). Nessa ótica de repúdio ao discurso parlamentar de ódio, o Poder Judiciário, para além da resolução de lides que envolvam a ruptura da imunidade material dos parlamentares, tem se manifestando no sentido de chamar à ordem o significado do hate speech dentro do âmbito político enquanto prática inconstitucional contra direitos fundamentais.

[...] 'Em nenhuma circunstância e sob nenhum pretexto, o discurso de um parlamentar - que não fala por si e nem apenas por seus eleitores, mas por toda a sociedade - pode contrastar os fundamentos e objetivos da República, valores imprescindíveis a um Estado Democrático de Direito, tais como a dignidade da pessoa humana (artigo $2^{\circ}$, III, da Constituição) e a erradicação de preconceitos de origem, raça, sexo, cor, idade e quaisquer outras formas de discriminação (artigo $3^{\circ}$, IV, da Constituição), notadamente aqueles que impliquem ataques discriminatórios a setores sociais historicamente vulneráveis', alertam os juízes (MACEDO; AFFONSO, 2014).

Por sua absoluta desfaçatez, duas manifestações particulares são aqui dignas de nota. Apoiando a escalonar cultura do estupro no país, sempre alimentada pela discriminação de gênero, Jair Bolsonaro teve a ousadia de dizer à deputada federal Maria do Rosário em plenário da Câmara dos Deputados que não a estupraria por que ela não merecia, devido ao seu gosto e à sua aparência física (cf. SCOCUGLIA; MUNIZ, 2016). A incitação ao crime de estupro é evidente: a mensagem subliminar afirma que há mulheres que merecem ser estupradas. Tendo o Ministério Público Federal oferecido queixa-crime contra o deputado, alegando que a imunidade parlamentar não era aplicada ao caso concreto, uma vez que o teor do discurso não possuía correlação com o exercício do mandato, em acolhimento da denúncia o relator da ação penal, o ministro Luiz Fux, escreveu que "não se pode subestimar os efeitos dos discursos que reproduzem um rebaixamento da dignidade da mulher e que podem gerar perigosas consequências sobre a forma como muitos irão considerar essa hedionda prática criminosa, que é o crime de estupro, podendo efetivamente encorajar a sua prática" (SUPREMO TRIBUNAL FEDERAL, 2016). Em outro dia de fúria, Jair Bolsonaro não somente exalou ofensas indiscriminadamente, 
como gerou constrangimento histórico ao fazer apologia à tortura. Durante a votação do assim denominado impeachment da presidenta Dilma Rousseff na Câmara dos Deputados, o parlamentar aclamou a honra do coronel Carlos Brilhante Ustra, cuja atuação, através da chefia do Destacamento de Operações de Informação - Centro de Operações de Defesa Interna (DOI-CODI), fora imprescindível para a naturalização da tortura como prática comum no regime empresarial-militar brasileiro inaugurado em 1964. Como retaliação, a Ordem dos Advogados do Brasil (OAB/RJ) apresentou seu repúdio ao discurso proferido, requerendo junto ao Supremo Tribunal Federal a abertura do processo penal e a perda de mandato do parlamentar, sob o argumento de que a imunidade parlamentar não pode ser instrumento de resguardo para o cometimento de crimes e atentados ao decoro parlamentar (cf. SOUZA, 2016).

\section{CONSIDERAÇÕES FINAIS}

A título de considerações finais, podemos salientar que estas breves linhas trazem apenas alguns exemplos mais redundantes, mais para pautar as questões aqui suscitadas do que para oferecer um conjunto exaustivo. Outros poderiam ser colhidos. Pior, outros exemplos virão à tona nos próximos meses. As atuações do Ministério Público e do Poder Judiciário, normalmente apontadas como o remédio constitucional para combater e dissuadir o discurso de ódio, são ainda insuficientes, e talvez sempre o sejam, tendo em vista que o problema é de fundo cultural. Mesmo que não nos seja possível conceber soluções fáceis para o problema da acareação entre a liberdade de expressão e as contradições do discurso político, que muitas vezes beiram o ódio livremente desafogado, torna-se urgente denunciar.

É preciso combater a discriminação e a violência para que nossa sociedade corresponda de modo visceral à pluralidade que a constitui. Devemos procurar anular a assunção da diferença como inferioridade, para superar a segregação, a dominação e a opressão contra grupos sociais minoritários, assim considerados por sua vulnerabilidade social. Sendo o problema de fundo cultural, ainda estamos longe de alcançar resultado feliz ou mesmo de identificar a melhor estratégia nesse sentido. E pensamos que investir em um direito punitivo não seja o melhor caminho. A cultura se alimenta da educação e se modifica com práticas educativas bem 
orientadas. É preciso, então, investir em educação, a fim de evitar todo tipo de marginalização, tanto nos discursos e atos deliberados, quanto nos inconscientes, também para não se tornar um cúmplice. Esse é o caminho.

\section{REFERÊNCIAS}

AGAMBEN, G. La comunità che viene, Torino: Bollati Boringhieri, 2001.

ANTUNES, D. C. Tolerância e democracia hoje: o discurso de deputados em defesa da posição conservadora, Psicologia \& Sociedade, Associação Brasileira de Psicologia Social, Porto Alegre, v. 28, n. 1, 2016, p. 03-13. Disponível em <http://www.scielo.br/pdf/psoc/v28n1/1807-0310-psoc-28-01-00003.pdf >. Acesso em 26 fev. 2017.

ARENDT, H. A condição humana. Tradução de Roberto Raposo, Rio de Janeiro: Forense Universitária, 2004.

BENTO, L. V. Parâmetros internacionais do direito à liberdade de expressão, Revista de Informação Legislativa (RIL), Brasília, a. 53, n. 210, p 93-115, abr./jun. 2016, Disponível em <http://www2.senado.leg.br/bdsf/bitstream/handle/id/ 522900/0010731 92.pdf>. Acesso em 26 mar. 2017.

BOBBIO, N. Elogio da serenidade e outros escritos morais. Traduçãoo de Marco Aurélio Nogueira, São Paulo: UNESP, 2002.

BOSIGNOLI, V. O. Abuso de Autoridade. Rev. Direito, Rio de Janeiro, v. 3, n. 6, p. 37-56. jul./dez. 1999. Disponível em: <http://www.camara.rj.gov.br/setores/pr oc/revistaproc/revproc1999/revdireito1999B/art_abusoimunidade.pdf>. Acesso em 25 mar. 2017.

BRASIL. Constituição da República Federativa do Brasil, Vade Mecum Acadêmico de Direito. São Paulo: Rideel, 2017.

BRASIL. Supremo Tribunal Federal. Inquérito 3.590 Distrito Federal, Acórdão de inteiro teor de 12/08/2014. Disponível em <http://redir.stf.jus.br/paginadorpub/pagi nador.jsp?docTP=TP\&docID=6717176>. Acesso em 19 de março de 2017.

BRASIL. Supremo Tribunal Federal. STF recebe denúncia contra deputado Jair Bolsonaro por incitação ao crime de estupro. Notícias STF, Brasília, 21 jun. 2016. Disponível em <http://www.stf.jus.br/portal/cms/verNoticiaDetalhe.asp?idCon teudo=319431>. Acesso em 19 mar. 2017.

FREITAS, R. S.; CASTRO, M. F. Liberdade de expressão e discurso do ódio: um exame sobre as possíveis limitações à liberdade de expressão, Seqüência (Florianópolis), n. 66, p. 327-355, jul. 2013. Disponível em: <http://www.scielo.br/ pdf/seq/n66/14.pdf>. Acesso em: 04 mar. 2017. 
GÓIS, F. Bolsonaro é condenado por declarações sobre gays. Congresso em foco, 14/04/2015. Disponível em: <http://congressoemfoco.uol.com.br/noticias/ bolsonaro-e-condenado-por-declaracoes-contra-gays/>. Acesso em: 29 maio 2017.

MACEDO, F.; AFFONSO, J. Juízes repudiam 'discurso de ódio' de Bolsonaro. Estadão, São Paulo, 11 dez. 2014. Disponível em: <http://politica.esta dao.com.br/blogs/fausto-macedo/juizes-repudiam-discurso-de-odio-de-bolsonaro/>. Acesso em: 26 mar. 2017.

RIO DE JANEIRO. Tribunal de Justiça do Estado. Jair Bolsonaro é condenado por declarações contra homossexuais. Notícia publicada pela Assessoria de Imprensa em 13 abr. 2015. Disponível em <http://www.tjrj.jus.br/ca_ES/home/-/noti cias/visualizar/10101>. Acesso em 19 mar. 2017.

RODEGHERI, L. B. A Teoria dos Princípios de Robert Alexy aplicada às colisões de direitos fundamentais ocorridas na Internet, Revista da AJURIS (Associação dos Juízes do Rio Grande do Sul), Porto Alegre, v. 42, n. 138, p. 87-107, jun. 2015. Disponível em <http://www.ajuris.org.br/OJS2/index.php/REVAJURIS/article/vi ewFile/511/Ajuris138_DT4>. Acesso em 18 mar. 2017.

SANTOS, R. H. Discurso do ódio: hate speech in substance no parlamento brasileiro. X SEPesq - Semana de Extensão, Pesquisa e Pós-graduaç̧ão, Centro Universitário Ritter dos Reis, 2014. Disponível em <https://www.uniritter.edu.br/uplo ads/eventos/sepesq/x_sepesq/arquivos_trabalhos/2968/343/338.pdf>. Acesso em 18 mar. 2017.

SCHÄFER, G.; LEIVAS, P. G. C.; SANTOS, R. H. Discurso de ódio: da abordagem conceitual ao discurso parlamentar, Revista de Informação Legislativa (RIL), Brasília, a. 52, n. 207, p. 143-158, jul./set. 2015. Disponível em: <http://www2.sena do.leg.br/bdsf/bitstream/handle/id/515193/001049120.pdf>. Acesso em: 27 fev. 2017.

SCOCUGLIA, L.; MUNIZ, M. Jandira e Bolsonaro testam limites de imunidade parlamentar no STF. Revista Eletrônica Jota, 23 jun. 2016. Disponível em <https://jota.info/justica/jandira-e-bolsonaro-testam-limites-de-imunidade-parlamentar -no-stf-23062016>. Acesso em 19 mar. 2017.

SOUZA, G. OAB-RJ pede cassação do mandato de Bolsonaro por homenagem a Ustra. Consultor Jurídico, 25 abr. 2016. Disponível em:

<http://www.conjur.com.br/2016-abr-25/oab-rj-cassacao-mandato-bolsonaro-homena gem-ustra>. Acesso em 26 mar. 2017.

TÔRRES, F. C. O direito fundamental à liberdade de expressão e sua extensão, Revista de Informação Legislativa (RIL), Brasília, a. 50, n. 200, p. 61-80, out./dez. 2013. Disponível em <https://www2.senado.leg.br/bdsf/bitstream/handle/id/502937/0 00991769.pdf?sequence =1>. Acesso em: 26 mar. 2017.

\section{Artigo recebido em: $13 / 05 / 2017$}

Artigo aprovado em: 25/05/2017 